\title{
Oyster Shell as a Low-Cost Adsorbent for Removing Heavy Metal Ions from Wastewater
}

\author{
Xin Xu${ }^{1}$, Xiaofeng Liu ${ }^{2}$, Myounghak $\mathrm{Oh}^{3}$, Junboum Park ${ }^{1 *}$ \\ ${ }^{1}$ Department of Civil and Environmental Engineering, Seoul National University, Seoul, South Korea \\ ${ }^{2}$ College of Architecture and Civil Engineering, Taiyuan University of Technology, Taiyuan, China \\ ${ }^{3}$ Coastal Disaster Prevention Research Center, Korea Institute of Ocean Science and Technology, \\ Busan, South Korea
}

Received: 22 March 2018

Accepted: 5 July 2018

\begin{abstract}
Oyster shell powder is a potential adsorbent material that can be used to control pollution in groundwater. The current research objective is to evaluate the heavy metal ion adsorption properties by oyster shell powder in an aqueous solution. Three kinds of heavy metals (copper, cadmium, and lead) were adsorbed using oyster shell powder from aqueous solution. The effects of different temperatures, contact times, $\mathrm{pH}$ values, and initial concentrations were examined in order to optimize the conditions used for heavy metal decontamination. Cadmium and copper adsorption behaviours were suitable for modelling by the Langmuir isotherm, and lead adsorption behaviour was best modelled by the Freundlich isotherm. Adsorption situations fitted a pseudo second-order kinetic model. Intraparticular diffusion of heavy metal ions by oyster shell powder could be divided into two stages: rapid diffusion first, followed by a stable second stage. The maximum adsorption amount was ranked in an ascending order as that to copper, cadmium, and then lead for both single and competitive systems. The adsorption capacities of copper, cadmium, and lead ions by oyster shell powder were lower in a competitive system than in a single system, indicating that competitive adsorption could occur.
\end{abstract}

Keywords: heavy metal ions, oyster shell, adsorption isotherm, adsorption kinetics, competitive adsorption

\section{Introduction}

Heavy metal pollution in groundwater is a global problem: it is important to deal with heavy-metalrich effluents. These effluents always carry significant toxicity to living beings when released to the environment. Thus effective treatment countermeasures

*e-mail: junbpark@snu.ac.kr should be taken before the emission of heavy metalcontaminated water into the environment [1]. There are some widely used methods for treatment of heavy metal-contaminated water, such as electrolytic recovery, chemical precipitation, soil washing, and so on; however, these conventional methods can pose some significant and successive problems such as the disposal of the precipitated wastes and high incurred cost $[2,4]$.

Adsorption is a more efficient method that has been widely studied and utilized for heavy metal ion uptake in wastewater and contaminated groundwater $[5,6]$. 
Activated carbon is an effective adsorbent material for wastewater treatment, but it is expensive and often unaffordable for developing countries [7]. In particular, a number of small-scale industries cannot afford the high-cost treatment technology to cope with the problems of heavy metal pollution [8,9]. Alternative adsorption technologies using budget materials (such as clay, sewage sludge, and coal fly ash) as adsorbents have been developed to become effective methods for removing heavy metal ions from an aqueous solution [10-12].

The western and southern coasts of South Korea abound with oysters and more than 0.32 million tons of waste oyster shells are produced each year [13]. It is indeed hard work to dispose of so many waste oyster shells [14]. If those waste oyster shells are not properly treated and stockpiled, the residual flesh thereof will slowly rot and emit odour, or the salts therein will decompose into gases (such as $\mathrm{H}_{2} \mathrm{~S}, \mathrm{NH}_{3}$, and amines) under the activities of various microorganisms. Waste oyster shell disposal has become a serious problem and we should spare no effort to seek new recycling methods for them [15].

Oyster shell, as a recyclable material, offers the potential for adsorption in the removal of heavy metal ions from wastewater and contaminated groundwater $[16,17]$. Reusing oyster shell as an alternative, low-cost, and non-toxic adsorption material not only reduces the environmental impact thereof, but also adds economic and utility values to it as a waste material $[18,19]$. Much research has been conducted on the adsorption characteristics of oyster shell for heavy metal removal [20-23]. Accordingly, the reuse of waste oyster shell as an adsorption material for wastewater remediation not only provides a new method of environmental modification, but also adds to the value of waste, therefore contributing to the development of the oyster meat trade in South Korea [24, 25].

The main objective of this study was to investigate the adsorption potential of oyster shell as an effective adsorbent for metallic ion uptake in solution and to characterize oyster shell adsorption mechanisms. Batch adsorption experiments were carried out to study the effects of contact time, $\mathrm{pH}$ value, temperature, and initial concentration on its adsorption efficiency. Copper, cadmium, and lead adsorption by oyster shell powder (OSP) was compared to give a better understanding of the adsorption preferences, and competitive adsorption was investigated in competitive systems of three kinds of heavy metal ion mixtures. The adsorption isotherms and kinetics were investigated to explain the adsorption behavior of heavy metal ions by OSP.

\section{Materials and Methods}

\section{Adsorbent Preparation}

The waste oyster shell was collected in Noryangjin Fish Market in Seoul, South Korea and washed in distilled water to remove residual musculature and sediments, then dried in air. They were heated at $110^{\circ} \mathrm{C}$ for $72 \mathrm{~h}$ to remove organic materials and attached sediment particles on the surface. Oyster shells were pulverized using mortar and pestle, then the powder was passed through a \#16 sieve $(1.18 \mathrm{~mm})$ and retained on a \#20 sieve $(0.85 \mathrm{~mm})$ to obtain homogeneous bulky porous particles with relatively uniform spherical diameter. The smaller the particular size, the higher the surface area for per unit mass of OSP, which can eventually lead to a higher adsorption rate of heavy metal ions by OSP; however, OSP with too small a grain size is easily lost when treated with contaminated water.

\section{Characteristics of OSP}

We observed the chemical compositions of OSP in an X-ray fluorescence (XRF) spectrometer and analyzed the microstructure of OSP under FE-SEM. The specific surface area was determined according to BET theory. Table 1 shows the physical properties of OSP with diameters ranging from $0.85 \mathrm{~mm}$ to $1.18 \mathrm{~mm}$. Table 2 shows the chemical composition of OSP: as can be seen, OSP comprised nearly $94.6 \% \mathrm{CaO}$.

\section{Adsorption Experiment}

Copper, cadmium, and lead solutions were prepared by dissolving $\mathrm{Cu}\left(\mathrm{NO}_{3}\right)_{2} \cdot 2 \mathrm{H}_{2} \mathrm{O}, \mathrm{Cd}\left(\mathrm{NO}_{3}\right)_{2} \cdot 4 \mathrm{H}_{2} \mathrm{O}$, and $\mathrm{Pb}\left(\mathrm{NO}_{3}\right)_{2}$ in distilled water, respectively. The analytical

Table 1. Physical properties of OSP.

\begin{tabular}{|c|c|c|c|}
\hline Particle size $(\mathrm{mm})$ & Bulk density $\left(\mathrm{g} / \mathrm{cm}^{3}\right)$ & Porosity $(\%)$ & Surface $\operatorname{area~}\left(\mathrm{m}^{2} / \mathrm{g}\right)$ \\
\hline $0.85-1.18$ & 1.46 & 73.22 & 2.13 \\
\hline
\end{tabular}

Table 2. Chemical components of OSP.

\begin{tabular}{|l|c|c|c|c|c|c|c|c|c|c|}
\hline Composition & $\mathrm{SiO}_{2}$ & $\mathrm{Al}_{2} \mathrm{O}_{3}$ & $\mathrm{Fe}_{2} \mathrm{O}_{3}$ & $\mathrm{MgO}$ & $\mathrm{CaO}$ & $\mathrm{Na}_{2} \mathrm{O}$ & $\mathrm{K}_{2} \mathrm{O}$ & $\mathrm{MnO}$ & $\mathrm{P}_{2} \mathrm{O}_{5}$ & L.O.I \\
\hline Content (\%) & 0.240 & 0.013 & 0.033 & 0.550 & 94.586 & 1.100 & 0.040 & 0.007 & 0.110 & 3.321 \\
\hline
\end{tabular}

Note: L.O.I $=$ Loss on ignition 
grade heavy metal nitrates were produced by the Junsei Chemical Company (Japan). A batch adsorption experiment was undertaken to investigate effects of temperature, contact time, $\mathrm{pH}$ value, and initial concentration on adsorption of heavy metal ions from an aqueous solution by OSP. All working volumes of heavy metal solutions were set to $40 \mathrm{~mL}$ at a room temperature of $24^{\circ} \mathrm{C}$ in $50 \mathrm{~mL}$ plastic conical tubes and shaken using a spin-shaker for 24 hours. The mass of OSP in each sample was set to $0.5 \mathrm{~g}$. The samples, after adsorption, were filtered through $0.45 \mu \mathrm{m}$ analytical filter papers and the $\mathrm{pH}$ values of the adsorption solutions were measured. The concentrations were analyzed by an atomic absorption spectrophotometer (AAS, Analytik Jena G, DE/novAA 300).

Competitive adsorption experiments were conducted by preparing heavy metal ion solutions containing lead, copper, and cadmium. Then the adsorption results in both single and competitive systems were compared. All adsorption experiments were performed in triplicate. The amount of heavy metal ions adsorbed by OSP $\left(Q_{\mathrm{e}}\right)$ was calculated using equation (1); the removal ratio $(R)$ can be calculated based on equation (2):

$$
\begin{gathered}
Q_{e}=\frac{\left(C_{0}-C_{e}\right) \cdot V}{m} \\
R=\frac{C_{0}-C_{e}}{C_{0}} \times 100 \%
\end{gathered}
$$

...where $C_{0}$ is initial concentration in the aqueous solution; $C_{\mathrm{e}}$ is equilibrium concentration in the aqueous solution; $m$ is mass of OSP; and $V$ is volume of the aqueous solution.

Adsorption isotherms and kinetics were investigated separately considering the effects of contact time and initial concentration on the maximum amount of adsorption. The metal affinity of adsorption was introduced to investigate heavy metal ion retention on OSP in the adsorption process.

\section{Results and Discussion}

\section{Adsorption Characteristics of OSP}

\section{Temperature}

The results of heavy metal ion adsorption tests on OSP at different temperatures $\left(8,12,16,20\right.$, and $\left.24^{\circ} \mathrm{C}\right)$ are shown in Fig. 1. The test was conducted without shaking at an initial concentration of $60 \mathrm{ppm}$. With increasing temperature, the amount of adsorbate on the OSP also increased and the best efficiency was obtained at the highest temperature of $24^{\circ} \mathrm{C}$ for all kinds of heavy metal ions assayed during the adsorption process. The temperature had the greatest effects and

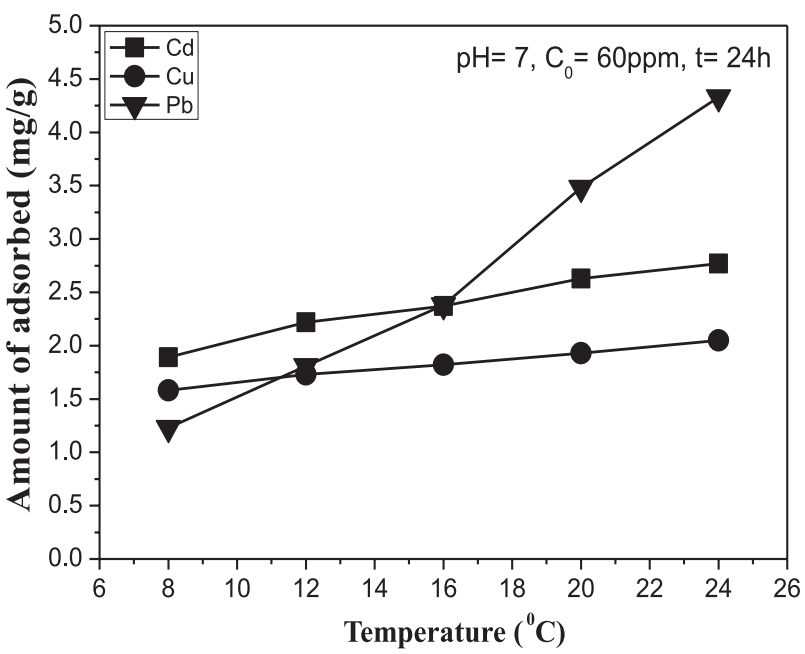

Fig. 1. Relationship between temperature and amount of heavy metal ions adsorbed by OSP.

highest affinity for lead adsorption by OSP among the three heavy metal ions. The higher adsorption amount could be attributed to either higher affinity of sites for heavy metal ions or many more binding sites being available on the relevant particle surface at higher temperatures. With increasing temperature, the number of available adsorption sites on the OSP surface also increased. It would seem that the more energetic the adsorption system, the stronger the heavy metal ion adsorption on OSP [26]. Lead was found to be the most sensitive to temperature change among other types of ions assayed here.

\section{Contact Time}

Contact time was a significant influential factor that could affect adsorption efficiency, and the test results could be used to confirm the equilibrium time and describe the adsorption kinetics [27]. Adsorption experiments with various contact times $(30,60,100$, $200,300,400,900$, and $1400 \mathrm{~min}$ ) were investigated at an initial heavy metal concentration of 60 ppm. Fig. 2 illustrates that the amount of heavy metal ions adsorbed onto OSP increased quickly with the increase of contact time and then tended to be stable. The heavy metal ion adsorption process was immediate and the adsorption rate was higher at the start of the experiment (before 200 minutes) than later in the experiment. This was due to the sufficient number of available sites on the OSP surface at the beginning of the adsorption process. As the adsorption sites were occupied, the adsorption rate of heavy metal ions decreased until saturation. Generally, since cadmium and lead adsorption by OSP reached equilibrium in 200 minutes, the maximum removal was obtained at the equilibration time of 200 minutes, and was then stabilized. Copper adsorption by OSP reached equilibrium and maximum removal in 400 minutes, and maximum removal was obtained after 


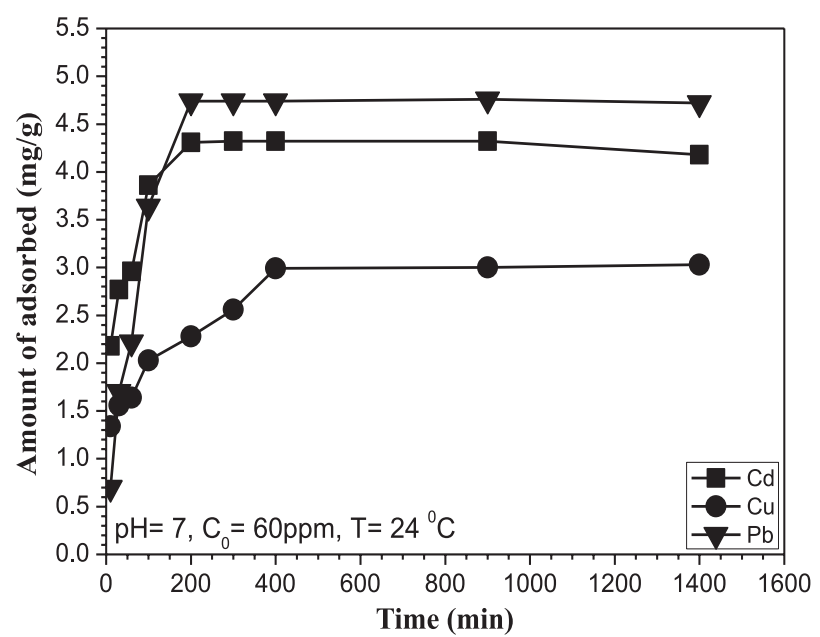

Fig. 2. Relationship between contact time and amount of heavy metal ions adsorbed by OSP.

400 minutes of equilibration. The results indicated that it was easier to reach equilibrium with cadmium and lead than with copper, and that cadmium and lead had a higher adsorption removal rate than copper under the same conditions. This trend is similar to that observed elsewhere [28].

\section{pH Value}

Initial $\mathrm{pH}$ value affected heavy metal ion removal by OSP. Test results for copper, cadmium, and lead ion adsorption by OSP, when the $\mathrm{pH}$ value was changed from 2 to 7, are shown in Fig. 3. Precipitation of heavy metals mainly occurred at $\mathrm{pH}>7$, and thus the adsorption tests were conducted at $\mathrm{pH}<7$. The amount of heavy metal ions adsorbed onto OSP was sensitive to $\mathrm{pH}$ variations in the test range of $2 \leq \mathrm{pH} \leq 7$. The amount of heavy metal ions adsorbed increased as the $\mathrm{pH}$ rose from 2 to

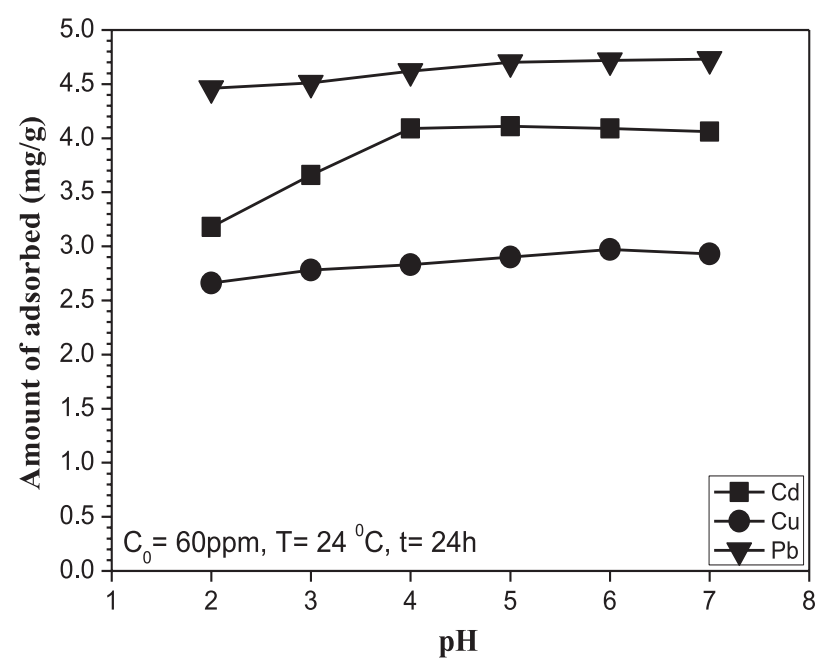

Fig. 3. Relationship between $\mathrm{pH}$ value and amount of heavy metal ions adsorbed by OSP.
6 and reached maximum at $5 \leq \mathrm{pH} \leq 6$. With increasing $\mathrm{pH}$, the ion removal ratio also increased. This was not only because of the hydrogen ions acting in competition with heavy metal ions at low $\mathrm{pH}$, but also owing to the sorbate lyophobic behaviour [29]. Adsorption sites on the adsorbent surface, and the degree of ionisation of heavy metal ions during the reaction, might be influenced by $\mathrm{pH}$ during the adsorption process. When the $\mathrm{pH}$ increased from 2 to 6 , the adsorbent surface became negatively charged and the interaction between heavy metal ions and binding sites gradually intensified in the aqueous solution. A similar trend was reported by a number of authors after tests on various adsorbents $[26,30]$.

\section{Initial Concentration}

Initial concentration affects the heavy metal uptake mechanism. Fig. 4 shows test results pertaining to the OSP adsorption process at different initial concentrations (20, 40, 60, 80, 100, 120, 200, 300, and 400 ppm). From

a)
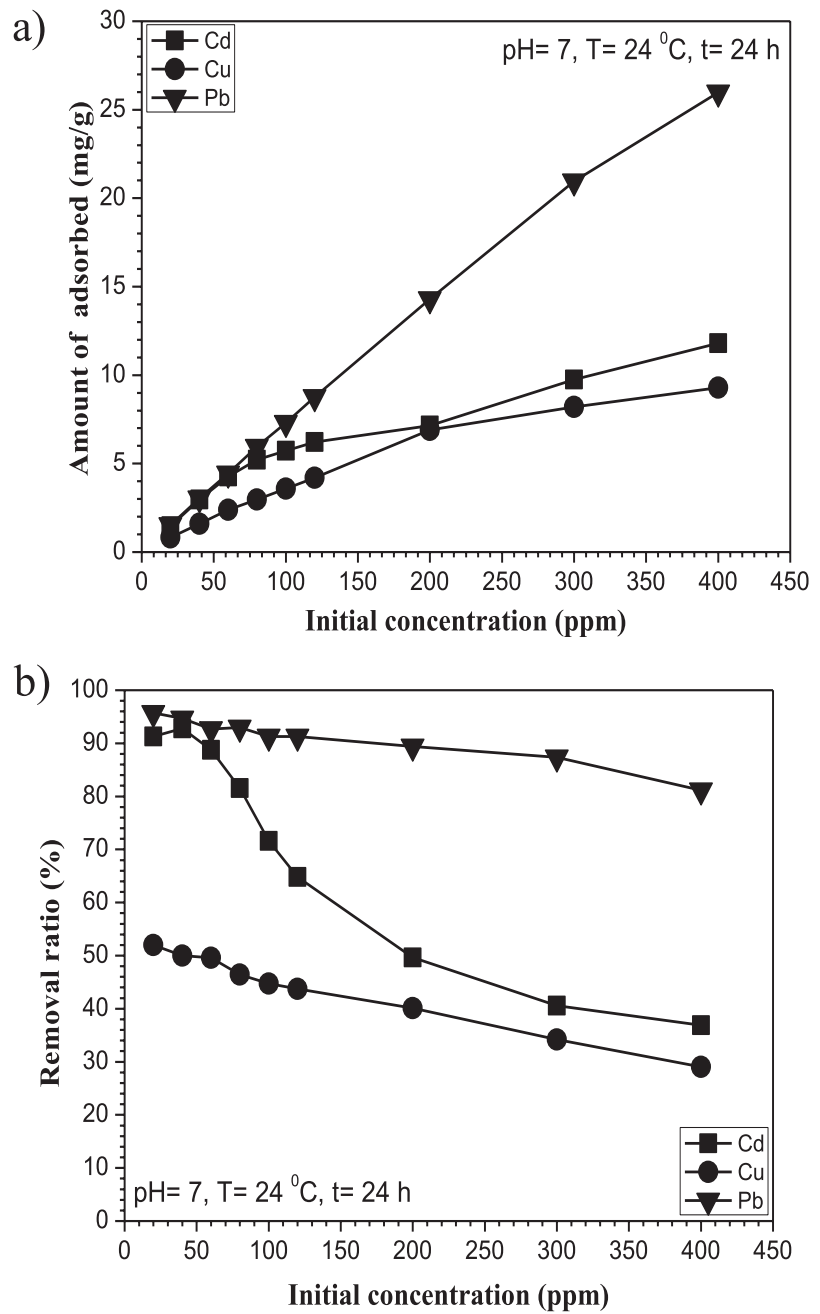

Fig. 4. Effect of initial concentration on the adsorption result: a) Relationship between amount of heavy metal ions adsorbed by OSP and initial heavy metal concentration; b) Relationship between the removal ratio and initial heavy metal concentration. 
Table 3. Distribution coefficient $\left(\mathrm{K}_{\mathrm{d}}\right)$ for OSP at different concentrations.

\begin{tabular}{|c|c|c|c|c|c|c|c|c|c|}
\hline $\mathrm{K}_{\mathrm{d}}(\mathrm{L} / \mathrm{Kg}) \quad \mathrm{C}_{0}(\mathrm{ppm})$ & 20 & 40 & 60 & 80 & 100 & 120 & 200 & 300 & 400 \\
\hline $\mathrm{Cd}$ & 838.3 & 1033.1 & 631.1 & 353.9 & 201.9 & 147.2 & 64.5 & 54.6 & 46.7 \\
\hline $\mathrm{Cu}$ & 86.7 & 80.0 & 78.7 & 69.3 & 64.8 & 62.2 & 60.7 & 41.5 & 32.8 \\
\hline $\mathrm{Pb}$ & 1802.4 & 1425.9 & 1017.1 & 1057.8 & 834.3 & 834.3 & 672.9 & 551.6 & 344.5 \\
\hline
\end{tabular}

Fig. 4a) we can see the total heavy metal ions adsorbed by OSP increased with initial concentration. This could be attributed to the increased concentration gradient and the associated promotion of absorbate transfer from solution onto the adsorbent surface. For the three types of ions, maximum amounts thereof adsorbed were at an initial concentration of $400 \mathrm{ppm}$ and the ascending order of maximum amount of adsorption was: copper, cadmium, and lead under identical conditions. As shown in Fig. 4b), the removal ratio descended with increasing initial concentration. There were enough high-energy adsorption sites at low concentrations that resulted in high adsorption. When the initial concentration increased, energy adsorption sites gradually became saturated. Owing to the saturation of the adsorption sites, no more heavy metal ions could be adsorbed. This indicates that fewer available adsorption sites at a higher initial concentration led to a decrease in adsorption ratio [31].

\section{Heavy Metal Affinity of Adsorption}

Heavy metal affinity could affect the maximum amount of adsorption: the maximum amount of adsorption for different heavy metal ions could arise as a result of the affinities to a large extent. The heavy metal affinity was evaluated by the distribution coefficient:

$$
K_{d}=\frac{Q_{e}}{C_{e}}
$$

...where $K_{\mathrm{d}}$ is distribution coefficient that can be used to express the ratio of equilibrium adsorption amount by OSP to equilibrium concentration in the solution. The heavy metal $K_{\mathrm{d}}$ of adsorption is shown in Table 3. A high $K_{\mathrm{d}}$ indicates a high removal capacity of adsorbents and vice versa $[32,33]$.

\section{Adsorption Isotherm}

Adsorption isotherms are usually utilized to describe interaction between the adsorbent and the aqueous solution, and furnish information for understanding the nature of the reaction, which is significant when an adsorption system is to be designed [34]. Langmuir and Freundlich isotherm models are widely used for investigating and representing adsorption processes and mechanisms [35]. The Langmuir model is based on a hypothesis that only one layer adsorbates are adsorbed at the adsorbent surface, where the adsorption potential is constant, and the Freundlich model is an empirical application suited to highly heterogeneous surfaces [36].

Equation (4) describes the Langmuir system:

$$
\frac{C_{e}}{Q_{e}}=\frac{1}{a b}+\frac{C_{e}}{a}
$$

...where $a$ is saturation capacity and $b$ denotes saturation constant.
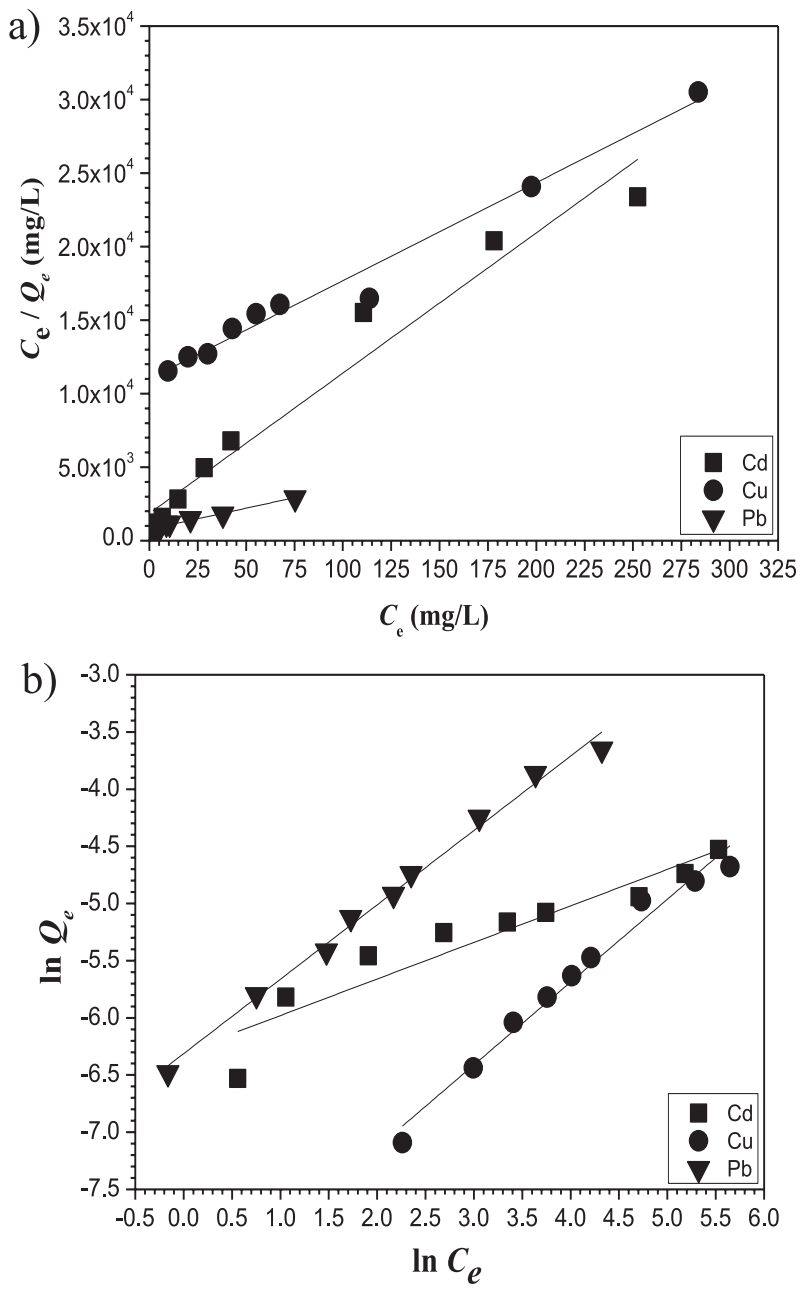

Fig. 5. Liner fitting of adsorption isotherms: a) Langmuir models of OSP at 20-400 ppm initial concentrations; b) Freundlich models of OSP at 20-400 ppm initial concentrations. 
Table 4. Langmuir and Freundlich models: fitted OSP adsorption parameters.

\begin{tabular}{|c|c|c|c|c|c|c|}
\hline \multirow{2}{*}{$\begin{array}{c}\text { Heavy } \\
\text { metal }\end{array}$} & \multicolumn{3}{|c|}{ Langmuir isotherm constants } & \multicolumn{3}{c|}{ Freundich isotherm constants } \\
\cline { 2 - 7 } & $1 / \mathrm{a}$ & $1 / \mathrm{ab}$ & $\mathrm{R}^{2}$ & $\mathrm{~K}_{\mathrm{F}}$ & $1 / \mathrm{n}$ & $\mathrm{R}^{2}$ \\
\hline Cadmium & 95.382 & 1859 & 0.964 & 1.234 & 0.320 & 0.893 \\
\hline Copper & 66.742 & 11001 & 0.981 & 1.813 & 0.725 & 0.979 \\
\hline Lead & 28.656 & 778 & 0.964 & 1.838 & 0.651 & 0.993 \\
\hline
\end{tabular}

Equation (5) describes the Freundlich isotherm:

$$
\ln Q_{e}=\ln K_{F}+\frac{1}{n} \ln C_{e}
$$

$\ldots$ where $K_{\mathrm{F}}$ is Freundlich isotherm constant and $1 / n$ is the Freundlich isotherm's intensity constant.

The linear fitting of these two kinds of isotherm models for OSP adsorption may be seen in Figs 5a) and $5 b)$. The fitting parameters are listed in Table 4 . We can see that all of the $\mathrm{R}^{2}$ values were between 0.893 and 0.993, revealing that cadmium and copper adsorption process was suitable for modelling by Langmuir adsorption isotherm and that the lead adsorption process was best modelled by use of the Freundlich adsorption isotherm. This indicated that the adsorption behaviour of cadmium and copper was single-layered on the surface of the OSP, whereas lead removal was a multilayered adsorption process, explaining why more lead ions could be adsorbed by OSP.

\section{Adsorption Kinetics}

The adsorption kinetics were introduced into adsorption research to describe the rate of the adsorption process [37]. The pseudo first-order (PFO) kinetic model is given by equation (6), the pseudo second-order kinetic model (PSO) is given by equation (7), and the intra-particular diffusion kinetic model is expressed by equation (8):

$$
\begin{gathered}
\log \left(Q_{e}-Q_{t}\right)=\log Q_{e}-k_{1} t \\
\left(t / Q_{t}\right)=\left[1 /\left(k_{2} Q_{e}^{2}\right)\right]+\left(1 / Q_{e}\right) t \\
Q_{t}=k_{d} t^{1 / 2}+c
\end{gathered}
$$

...where $t$ is adsorption time; $Q_{\mathrm{t}}$ is the amount of heavy metal ions adsorbed by the OSP at time $t$; and $k_{1}, k_{2}, k_{\mathrm{d}}$, and $c$ are the PFO, PSO, and intra-particular diffusion kinetic model constants.

The fitting parameters for PFO and PSO kinetic models are listed in Table 5. The linear PSO kinetic model provided much better $\mathrm{R}^{2}$ values $(0.999,0.998$, and 0.997) than the linear PFO kinetic model (0.481, 0.791, and 0.603). Thus, the adsorption situation followed a PSO kinetic model. The linear PSO kinetics for the adsorption of adsorbate ions by OSP can be seen in Fig. 6a). Fig. 6b) describes the particles diffusion of ions on OSP. There are two clear diffusion stages for each heavy metal ion, and the corresponding constants are listed in Table 6, from which the diffusion rate can be obtained. The heavy metal ions diffused rapidly on the OSP particles during the first stage, then the rate of diffusion decreased and tended to be stable thereafter $[38,39]$. Intra-particular diffusion was related to the porosity of the adsorbent, which could prevent OSP physisorption. The porosity of the OSP was initially high, and as the contact time increased, most pores became occupied by heavy metal ions, and thus the OSP physisorption increased until saturation [40].

\section{Competitive Adsorption}

Fig. 7a) shows the competitive adsorption of lead, copper, and cadmium by OSP in a competitive system: the amount of heavy metal ion adsorption increased at higher initial concentration in solution. Lead adsorption indicated the best efficiency compared with the other two heavy metals, which was similar to the situation seen in the single system. The maximum amount of adsorption in single and competitive systems are compared in Figs 7b) to 7d). The amount of heavy metal ions adsorbed in competitive systems was lower than that in single systems. The effect of heavy metal

Table 5. PFO and PSO kinetic model fitting parameters for OSP adsorption.

\begin{tabular}{|c|c|c|c|c|c|c|}
\hline \multirow{2}{*}{$\begin{array}{c}\text { Heavy } \\
\text { metal }\end{array}$} & \multicolumn{2}{|c|}{ Pseudo-first-order kinetic constants } & \multicolumn{3}{c|}{ Pseudo-second-order kinetic constants } \\
\cline { 2 - 7 } & $\mathrm{K}_{1}$ & $\mathrm{Q}_{\mathrm{e}}$ & $\mathrm{R}^{2}$ & $\mathrm{~K}_{2}$ & $\mathrm{Q}_{\mathrm{e}}$ & $\mathrm{R}^{2}$ \\
\hline Cadmium & 0.0024 & 0.65 & 0.481 & 0.018 & 5.39 & 0.999 \\
\hline Copper & 0.0022 & 1.53 & 0.791 & 0.0073 & 3.13 & 0.998 \\
\hline Lead & 0.0030 & 1.36 & 0.603 & 0.0049 & 4.96 & 0.997 \\
\hline
\end{tabular}



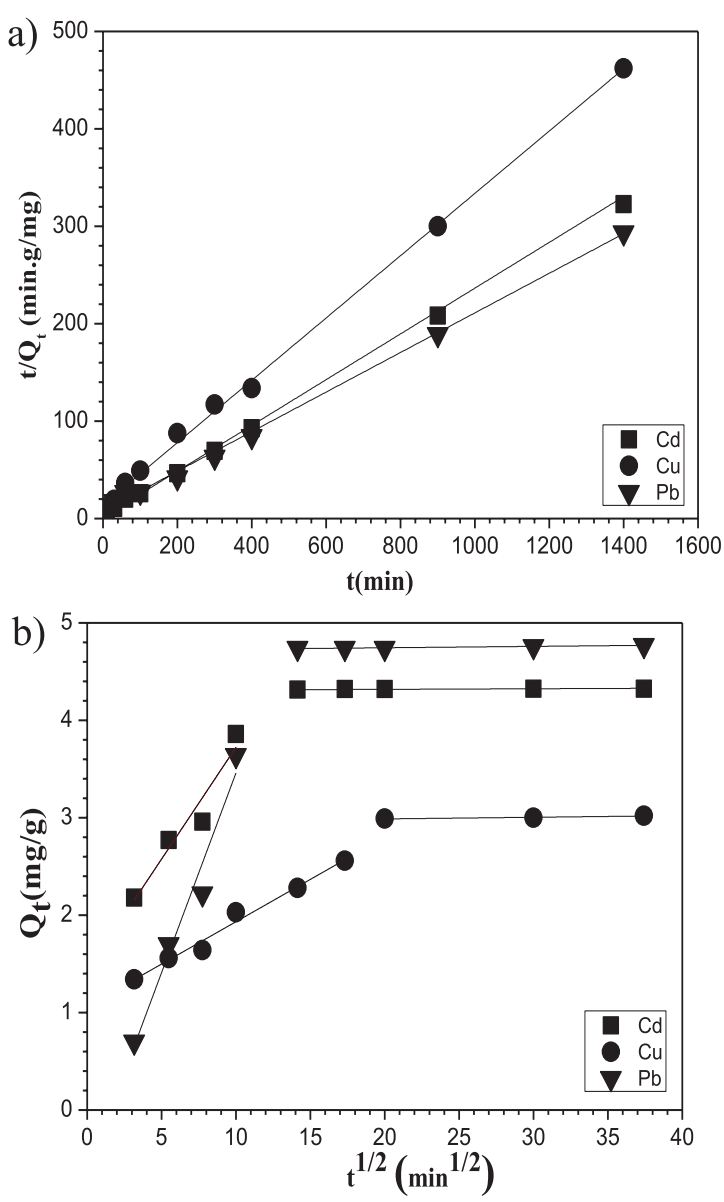

Fig. 6. Adsorption kinetics: a) Linear PSO kinetics models of OSP; b) Particles diffusion of heavy metal ions by OSP.

ion adsorption could be explained in that there were some competitive effects occurring on the surface of the OSP. In a competitive system, the adsorption of one type of ion on the OSP surface might affect the adsorption of other ions thereon. The amount of adsorption sites on the adsorbent surface that could adsorb metallic ions was limited and an ion adsorption could obstruct other ions' adsorption on OSP surfaces. As competition occurred, the amount of heavy metal ions adsorbed decreased in the competitive system. The number of adsorption sites needed for heavy metal ions in competitive systems would be much greater than in single systems. Competition between them would be more intense in the battle for certain adsorption sites. In other research, competitive adsorption was also found in binary systems [41-43].

Further analysis shows that the different amounts of heavy metal ions adsorbed onto OSP in single and competitive systems were more obvious at higher initial concentrations. Thus, competition gradually became stronger with increasing initial concentration. At low heavy metal concentrations, the adsorption sites were relatively abundant for all three heavy metals, since fewer adsorption sites were needed at low heavy metal concentrations [44].
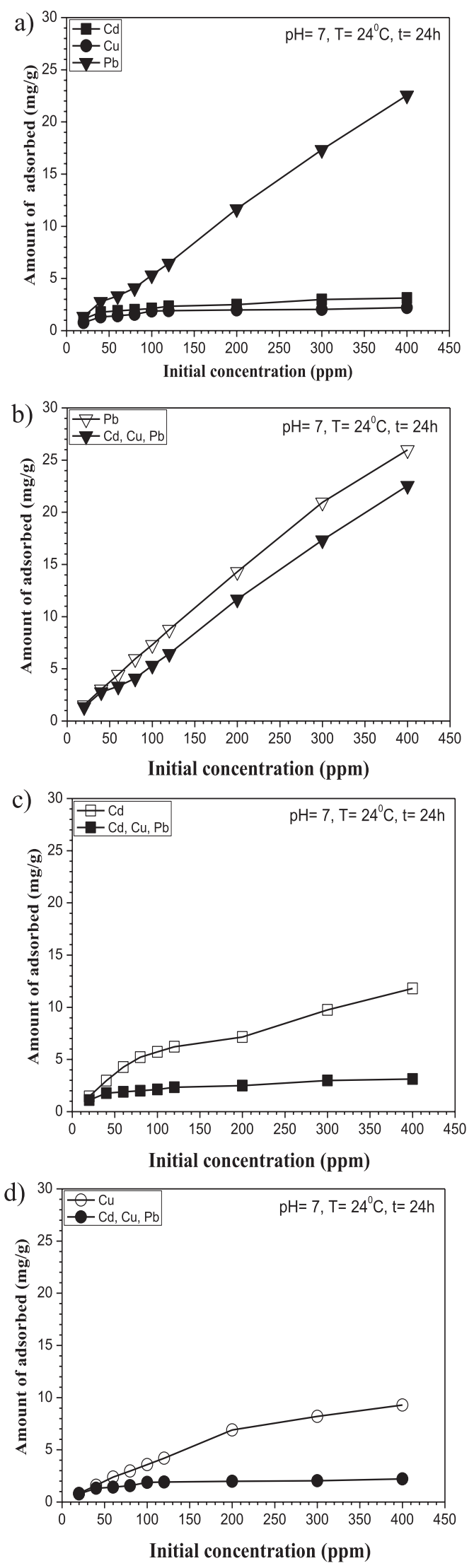

Fig. 7. Competition adsorption of heavy metal ions by OSP: a) Competition adsorption of heavy metal ions by OSP in competition system; b) Adsorption of Lead by OSP in single and competition systems; c) Adsorption of Cadmium by OSP in single and competition systems; d) Adsorption of Copper by OSP in single and competition systems. 
Table 6. Particles diffusion fitting parameters for OSP adsorption.

\begin{tabular}{|c|c|c|c|c|c|c|}
\hline \multirow{2}{*}{$\begin{array}{c}\text { Heavy } \\
\text { metal }\end{array}$} & \multicolumn{2}{|c|}{ Particle diffusion kinetic constants (first stage) } & \multicolumn{3}{|c|}{ Particle diffusion kinetic constants (second stage) } \\
\cline { 2 - 7 } & $\mathrm{K}_{\mathrm{d}}$ & $\mathrm{C}$ & $\mathrm{R}^{2}$ & $\mathrm{~K}_{\mathrm{d}}$ & $\mathrm{C}$ & $\mathrm{R}^{2}$ \\
\hline Cadmium & 0.23 & 1.43 & 0.91 & 0.0003 & 4.31 & 0.95 \\
\hline Copper & 0.086 & 1.064 & 0.98 & 0.0017 & 2.95 & 0.85 \\
\hline Lead & 0.41 & -0.64 & 0.95 & 0.0014 & 4.72 & 0.94 \\
\hline
\end{tabular}

Table 7. Enrichment coefficients for OSP adsorption in single and competitive systems.

\begin{tabular}{|c|c|c|c|c|c|c|c|c|c|c|}
\hline System & $\mathrm{C}_{0}(\mathrm{ppm})$ & 20 & 40 & 60 & 80 & 100 & 120 & 200 & 300 & 400 \\
\hline \multirow{3}{*}{ Single } & $\mathrm{E}_{(\mathrm{Cd})}$ & 0.91 & 0.93 & 0.89 & 0.82 & 0.72 & 0.5 & 0.45 & 0.41 & 0.37 \\
\hline & $\mathrm{E}_{(\mathrm{Cu})}$ & 0.52 & 0.5 & 0.49 & 0.47 & 0.45 & 0.44 & 0.43 & 0.34 & 0.29 \\
\hline & $\mathrm{E}_{(\mathrm{Pb})}$ & 0.96 & 0.95 & 0.93 & 0.93 & 0.91 & 0.91 & 0.89 & 0.87 & 0.81 \\
\hline \multirow{3}{*}{ Competition } & $\mathrm{E}_{(\mathrm{Cd})}$ & 0.69 & 0.56 & 0.39 & 0.31 & 0.27 & 0.24 & 0.16 & 0.12 & 0.1 \\
\hline & $\mathrm{E}_{(\mathrm{Cu})}$ & 0.49 & 0.41 & 0.3 & 0.25 & 0.24 & 0.2 & 0.12 & 0.09 & 0.07 \\
\hline & $\mathrm{E}_{(\mathrm{Pb})}$ & 0.84 & 0.87 & 0.69 & 0.64 & 0.67 & 0.67 & 0.73 & 0.72 & 0.70 \\
\hline
\end{tabular}

To evaluate the competitive adsorption capacities of heavy metal ions by the OSP in competitive adsorption systems, the enrichment coefficient (E) was used:

$$
E=\frac{m_{\text {sample }}}{m_{\text {solution }}} \times 100 \%
$$

...where $m_{\text {sample }}$ is the total amount of heavy metal ions adsorbed by OSP, and $m_{\text {solution }}$ is the total amount of heavy metal ions that were present in the aqueous solution before adsorption.

Table 7 lists the enrichment coefficient results of OSP adsorption in single and competitive systems. Enrichment coefficients of both systems for three types of ions uptake by OSP are, in ascending order: copper, cadmium, then lead. This sequence may be related to the radius, valid hydration radius, and heat of hydration of heavy metal ions.

\section{SEM Observations of Heavy Metal Ions Adsorption by OSP}

The microstructure of an oyster shell consists of a sheet phase and porous bulky layers: the porous bulky layer was sandwiched between two sheet phase layers [14]. In this research, we used the porous bulky layer as an adsorbent. The microstructures of OSP during preadsorption and post-adsorption phases, in heavy metal aqueous solution, are shown in Figs 8a) to 8d). SEM micrographs can depict the adsorption mechanism of metallic ions by OSP. Figs 8c) and 8d) show that the OSP surface was sparsely covered with precipitation product after the adsorption of copper and lead, which means that any copper and lead adsorbed by OSP arose as a result of secondary precipitation. Fig. 8b) shows some slight precipitation on the surface after the adsorption of cadmium, which means that the amount of cadmium adsorption onto OSP was low, or that the ions were attached to the surface. a)

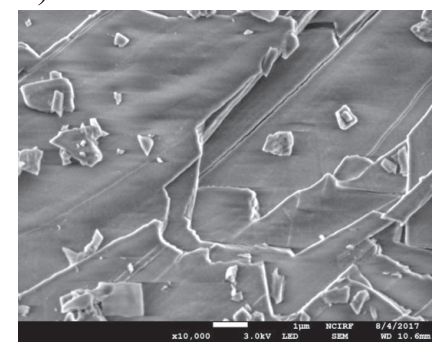

b)

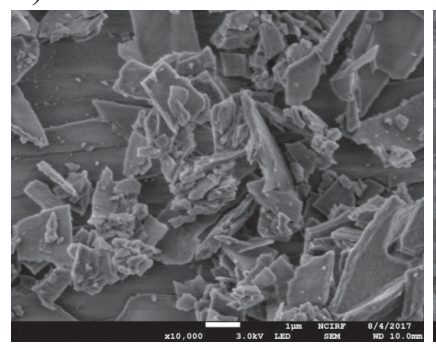

c)

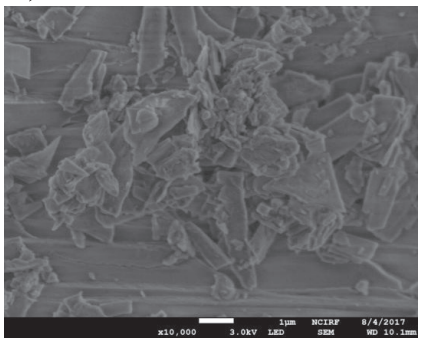

d)

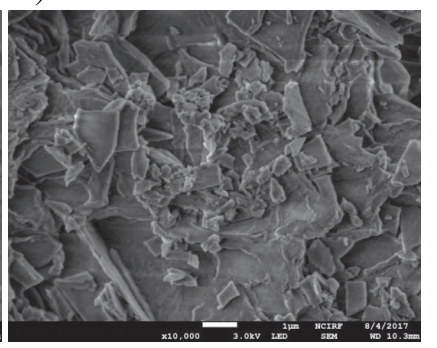

Fig. 8. SEM of OSP before and after adsorption of heavy metal ions: a) Before adsorption; b) After adsorption of cadmium; c) After adsorption of copper; d) After adsorption of lead. 


\section{Conclusions}

The adsorption of lead, cadmium, and copper on OSP (from an aqueous solution) was measured. The temperature, contact time, $\mathrm{pH}$ value, and initial concentration affected the heavy metal ion removal capacity of the OSP. The amount of heavy metal ions adsorbed on the OSP increased with increasing temperature, and the maximum amount of adsorption was obtained at $24^{\circ} \mathrm{C}$ for all three heavy metal ions tested herein. The amount of heavy metal ions adsorbed on the OSP increased with increasing contact time; cadmium and lead adsorption by OSP reached equilibrium in 200 minutes, copper adsorption by OSP reached equilibrium in 400 minutes, and the maximum amount of adsorption was obtained within the equilibration time. The amount of heavy metal ions adsorbed on the OSP was sensitive to $\mathrm{pH}$ variations within the test range $2 \leq \mathrm{pH} \leq 7$. Upon the increase of initial concentration, the amount of heavy metal ions adsorbed on the OSP increased and the removal ratio decreased.

Competitive adsorption was found on the OSP surface in heavy metal composite solutions. In ascending order, the maximum amount of adsorbed heavy metal ion was: copper, cadmium, and then lead, in both single and competitive systems.

Cadmium and copper adsorption could be fitted by use of the Langmuir isotherm, and lead adsorption behaviour could be described by the Freundlich isotherm. Adsorption kinetic models and the kinetic parameters indicated that the adsorption situation could be fitted by the PSO kinetic model. Intra-particular diffusion of heavy metal ions by OSP could be divided into two stages: the heavy metal ions diffused rapidly on OSP particles in the initial stage of the process, then the diffusion speed decreased and tended to be stable thereafter.

OSP had an adsorption structure conducive to heavy metal ion removal and the behaviour of heavy metal ions adsorbed on an OSP surface could be revealed through SEM analysis. OSP offers the potential for use as an adsorbent material that can be used in the treatment of wastewater in future applications. In addition, oyster shells will be modified by thermal treatment at various temperatures in future research, the maximum amount of adsorption and characteristics thereof will be compared with natural OSP to produce a potentially valuable adsorbent for wastewater and the contaminant heavy metals therein.

\section{Acknowledgements}

This research was part of the project titled 'Development on technology for offshore waste final disposal', funded by the Ministry of Oceans and Fisheries, South Korea, and a grant funding (17CTAP-C132706-01) from Infrastructure and Transportation Technology Promotion Research
Program funded by Ministry of Land, Infrastructure and Transport of South Korea, and supported by the Institute of Engineering Research at Seoul National University

\section{Conflict of Interest}

The authors declare no conflict of interest.

\section{References}

1. HU B., JIA X., HU J., XU D., XIA F., LI Y. Assessment of heavy metal pollution and health risks in the soil-plant-human system in the yangtze river delta, China. International Journal of Environmental Research \& Public Health, 14 (9), 1, 2017.

2. MEUNIER N., DROGUI P., MONTANÉ C., HAUSLER R., MERCIER G., BLAIS J.F. Comparison between electrocoagulation and chemical precipitation for metals removal from acidic soil leachate. Journal of Hazardous Materials, 137 (1), 581, 2006.

3. MOON D.H., PARK J.W., KOUTSOSPYROS A., CHEONG K.H., CHANG Y.Y., BAEK K., JO R., PARK J.H. Assessment of soil washing for simultaneous removal of heavy metals and low-level petroleum hydrocarbons using various washing solutions. Environmental Earth Sciences, 75 (10), 884, 2016.

4. FU F., WANG Q. Removal of heavy metal ions from wastewaters: a review. Journal of Environmental Management, 92 (3), 407, 2011.

5. AI P.L., ARIS A.Z. A review on economically adsorbents on heavy metals removal in water and wastewater. Reviews in Environmental Science \& Bio/technology, 13 (2), 163, 2014.

6. BISHT R., AGARWAL M., SINGH K. Heavy metal removal from wastewater using various adsorbents: a review. Journal of Water Reuse \& Desalination, 8 (1), 104, 2016.

7. KANG A.J., BAGHDADI M., PARDAKHTI A. Removal of cadmium and lead from aqueous solutions by magnetic acid-treated activated carbon nanocomposite. Desalination \& Water Treatment, 57 (40), 18782, 2016.

8. CHOWDHURY S., MAZUMDER M.A.J., AL-ATTAS O., HUSAIN T. Heavy metals in drinking water: occurrences, implications, and future needs in developing countries. Science of The Total Environment, 569-770 (1), 476, 2016.

9. BHATNAGAR A., HOGLAND W., MARQUES M., SILLANPÄÄ M. An overview of the modification methods of activated carbon for its water treatment applications. Chemical Engineering Journal, 219 (3), 499, 2013.

10. PARE S., PERSSON I., GUAL B., LUNDBERG D., ZERBO L., KAM S., TRAORE K. Heavy metal removal from aqueous solutions by sorption using natural clays from Burkina Faso, African Journal of Biotechnology, 11 (45), 10395, 2012.

11. TRIPATHI A., RANJAN M.R. Heavy metal removal from wastewater using low cost adsorbents. Journal of Bioremediation \& Biodegradation, 6 (6), 315, 2015.

12. HARJA M., BUEMA G., SUTIMAN D.M., CRETESCUI I. Removal of heavy metal ions from aqueous solutions 
using low-cost sorbents obtained from ash. Chemical Papers, 67 (5), 497, 2013.

13. JEONG S.H., LIM J.E., SANG S.L., CHANG Y.Y., MOON D.H., YONG S.O. Evaluation on remediation efficiency on acid-spilled soil using oyster shell and biochar. Journal of Agricultural, Life and Environmental Sciences, 25 (2), 10, 2013.

14. YOON G.L., KIM B.T., KIM B.O., HAN S.H. Chemicalmechanical characteristics of crushed oyster-shell. Waste Management, 23 (9), 825, 2003.

15. YONGSIK O., SANGEUN O., AHMAD M., LEE S.S. Effects of natural and calcined oyster shells on $\mathrm{Cd}$ and $\mathrm{Pb}$ immobilization in contaminated soils. Environmental Earth Sciences, 61 (6), 1301, 2010.

16. LEE C.W., KWON H.B., JEON H.P., KOOPMAN B. A new recycling material for removing phosphorus from water. Journal of Cleaner Production, 17 (7), 683, 2009.

17. LEE H.H., KIM S.Y., OWENS V.N., PARK, S., KIM, J., HONG, C.O. How does oyster shell immobilize cadmium? Archives of Environmental Contamination and Toxiology, 74 (1), 114, 2018.

18. WU Q., CHEN J., CLARK M., YU, Y. Adsorption of copper to different biogenic oyster shell structures. Applied Surface Science, 311 (9), 264-272, 2014

19. JEON D.Y., LEE K.S., SHIN H.M., OH K.J. Adsorption characteristics of heavy metals for waste sludge and oyster shell. Journal of Environmental Science International, The Korean Environmental Sciences Society, 15 (11), 1053, 2006.

20. ALIDOUST D., KAWAHIGASHI M., YOSHIZAWA S., SUMIDA H., WATANABE M. Mechanism of cadmium biosorption from aqueous solutions using calcined oyster shells. Journal of Environmental Management, 150 (1), 103, 2015.

21. GAO Y.J. Removal of heavy metals from synthetic landfill leachate using oyster shells adsorbent. Asian Journal of Chemistry, 25 (15), 8533, 2013.

22. HADI S., HASTUTI B., SETIAWATI N.T. Application of oyster (anadara inflata) shell chitosan as adsorbent for heavy metal $\mathrm{Cu}(\mathrm{ii})$ ion. Applied Mechanics \& Materials, 798, 390, 2015.

23. GAO Y., HUANG R., YAN J., WANG D. Study on adsorbing heavy metals using oyster shell. Shandong Chemical Industry, 44 (3), 1532015.

24. HSU T.C. Experimental assessment of adsorption of $\mathrm{Cu}^{2+}$ and $\mathrm{Ni}^{2+}$ from aqueous solution by oyster shell powder. Journal of Hazardous Materials, 171 (1/3), 995, 2009.

25. YONG S.O., LIM J.E., MOON D.H. Stabilization of $\mathrm{Pb}$ and $\mathrm{Cd}$ contaminated soils and soil quality improvements using waste oyster shells. Environmental Geochemistry \& Health, Springer, 33 (1), 83, 2011.

26. KILIÇ M., KIRBIYIK Ç., ÇEPELIOĞULLAR Ö., PÜTÜN A.E. Adsorption of heavy metal ions from aqueous solutions by bio-char, a by-product of pyrolysis. Applied Surface Science, Elsevier, 283 (14), 856, 2013.

27. TAN K.L., HAMEED B.H. Insight into the adsorption kinetics models for the removal of contaminants from aqueous solutions. Journal of the Taiwan Institute of Chemical Engineers, 74 (1), 25, 2017.

28. TEIMOURI A., ESMAEILI H., FOROUTAN R., RAMAVANDI B. Adsorptive performance of calcined cardita bicolor, for attenuating $\mathrm{Hg}$ (ii) and $\mathrm{As}$ (iii) from synthetic and real wastewaters. Korean Journal of Chemical Engineering, 35 (2), 479, 2018.
29. WANG L., LIU R.Q., HU Y.H., SUN W. pH effects on adsorption behavior and self-aggregation of dodecylamine at muscovite/aqueous interfaces. Journal of Molecular Graphics and Modelling, 67 (1), 62, 2016.

30. LUKMAN S., ESSA M.H., MU'AZU N.D., BUKHARI A., BASHEER C. Adsorption and desorption of heavy metals onto natural clay material: influence of initial $\mathrm{pH}$. Journal of Environmental Science and Technology, 6 (1), $1,2013$.

31. DEVI P., SAROHA A.K. Utilization of sludge based adsorbents for the removal of various pollutants: a review. Science of the Total Environment, 578 (1), 16 2017.

32. USMAN A.R.A., SALLAM A.S., AL-OMRAN A., EI-NAGGAR A.H., ALENAZI, K.K.H., NADEEM M., AL-UABEL M.I. Chemically modified biochar produced from conocarpus wastes: an efficient sorbent for $\mathrm{Fe}(\mathrm{ii})$ removal from acidic aqueous solutions. Adsorption Science \& Technology, 31 (7), 625, 2013.

33. AHMAD M., USMAN A.R.A., SANG S.L., KIM S.C., JOO J.H., YANG J.E. Eggshell and coral wastes as low cost sorbents for the removal of $\mathrm{Pb}^{2+}, \mathrm{Cd}^{2+}$, and $\mathrm{Cu}^{2+}$, from aqueous solutions. Journal of Industrial \& Engineering Chemistry, 18 (1), 198, 2012.

34. INAM E., ETIM U., EDUOK U., ESSIEN J. Heavy metals sorption potential of calcareous shells of animal origin. International Journal of Chemical, Environmental and Pharmaceutical Research, 3 (3), 184, 2012.

35. ADEBISI G.A., ALABA P.A. Equilibrium, kinetic, and thermodynamic studies of lead ion and zinc ion adsorption from aqueous solution onto activated carbon prepared from palm oil mill effluent. Journal of Cleaner Production, 148, 958, 2017.

36. BADAWI M.A., NEGM N.A., ABOU KANA M.T, HEFNI H.H., ABDEL MONEEM M.M. Adsorption of aluminum and lead from wastewater by chitosantannic acid modified biopolymers: isotherms, kinetics, thermodynamics and process mechanism International Journal of Biological Macromolecules, 99, 465, 2017.

37. ZHONG L., LI W., ZHANG Y., NORRIS P., CAO Y., PAN W.P. Kinetic studies of mercury adsorption in activated carbon modified by iodine steam vapor deposition method. Fuel, 188, 343-351, 2017.

38. IGBERASE E., OSIFO P., OFOMAJA A. The adsorption of $\mathrm{Pb}, \mathrm{Zn}, \mathrm{Cu}, \mathrm{Ni}$, and $\mathrm{Cd}$ by modified ligand in a single component aqueous solution: equilibrium, kinetic, thermodynamic, and desorption studies. International Journal of Analytical Chemistry, 2017 (2), 6150209, 2017.

39. NAMASIVAYAM C., SAKODA A., SUZUKI M. Removal of phosphate by adsorption onto oyster shell powder - kinetic studies. Journal of Chemical Technology \& Biotechnology, 80 (3), 356, 2005.

40. FULAZZAKY M.A. Determining the resistance of mass transfer for adsorption of the surfactants onto granular activated carbons from hydrodynamic column. Chemical Engineering Journal, 166 (3), 832, 2011.

41. PUTRO J.N., SANTOSO S.P., ISMADJI S., JU Y.H. Investigation of heavy metal adsorption in binary system by nanocrystalline cellulose - bentonite nanocomposite: improvement on extended langmuir isotherm model. Microporous \& Mesoporous Materials, 246, 166, 2017.

42. WANG F., PAN Y., CAI P., GUO T., XIAO H. Single and binary adsorption of heavy metal ions from 
aqueous solutions using sugarcane cellulose-based adsorbent. Bioresource Technology, 241, 482, 2017.

43. HAN L., QIAN L.B., LIU R.Q., CHEN M.F., YAN J.C., HU Q.H. Lead adsorption by biochar under the elevated competition of cadmium and aluminum. Scientific Reports, 7 (1), 2264, 2017.
44. OKOLI C.P., DIAGBOYA P.N., ANIGBOGU I.O., OLUOWOLABI B.I., ADEBOWALE K.O. Competitive biosorption of $\mathrm{Pb}(\mathrm{II})$ and $\mathrm{Cd}(\mathrm{II})$ ions from aqueous solutions using chemically modified moss biomass (Barbula lambarenensis). Environmental Earth Sciences, 76 (1), 33, 2017. 
